\title{
A retrospective study on indications and histopathological analysis of non-oncological hysterectomies in a tertiary care hospital
}

\author{
Ananthi Kasinathan, Himabindu Nagulapally*
}

Department of Obstetrics and Gynecology, Indira Gandhi Medical College and Research Institute, Kadirkamam, Puducherry, India

Received: 13 October 2020

Revised: 22 October 2020

Accepted: 23 October 2020

*Correspondence:

Dr. Himabindu Nagulapally,

E-mail: hbindu27@yahoo.co.in

Copyright: () the author(s), publisher and licensee Medip Academy. This is an open-access article distributed under the terms of the Creative Commons Attribution Non-Commercial License, which permits unrestricted non-commercial use, distribution, and reproduction in any medium, provided the original work is properly cited.

\begin{abstract}
Background: An increase in the number of women undergoing hysterectomy especially in South India is of great concern. Whenever hysterectomy is performed, it is imperative that clinical diagnosis is accurate. The purpose of current study is to assess whether the histopathological diagnosis after surgery is correlated with the clinical diagnosis.

Methods: This is a retrospective study conducted in the department of obstetrics and gynaecology at Indira Gandhi medical college and research institute Puducherry, from January 2018 to December 2018. Patients, who underwent hysterectomy for benign causes, were included in the study. Data was collected from the patients' case records. Whether the histopathological diagnosis was in tandem with the clinical diagnosis, was noted

Results: Out of the 234 hysterectomies performed, $46.15 \%$ were by abdominal route and $53.84 \%$ were by vaginal route. $24.7 \%$ were TAH with BSO with mean age of 49.72 years. VH with PFR (46.5\%) was the most common surgery done. Out of the 80 cases of fibroid, 66 (28.2\%) were confirmed on histopathology. Histopathological diagnosis corroborated the clinical diagnosis in patients with ovarian cyst, fibroid with ovarian cyst and DUB. Adenomyosis was validated in 7 of 9 cases. Endometriosis of ovary was confirmed in 4 (1.7\%) cases. In patients with pelvic organ prolapse, histopathology showed atrophic changes.

Conclusions: Accurate clinical diagnosis, supported by in-depth preoperative evaluation and a sound clinical knowledge helps to avoid unnecessary hysterectomies. It is imperative to study the histopathology of the operated specimen and confirm the appropriateness of the clinical indication.
\end{abstract}

Keywords: Hysterectomy, Clinical diagnosis, Histopathological diagnosis

\section{INTRODUCTION}

Hysterectomy is performed for a myriad of indications which includes both benign and malignant lesions. It provides relief to women from such benign gynaecological conditions like fibroid, abnormal uterine bleeding, uterovaginal prolapse in addition to malignancies. ${ }^{1}$ This leads to an improvement in their quality of life, especially 6 to 12 months after surgery. ${ }^{2-4}$ But these beneficial effects are overshadowed by postoperative complications like sexual dysfunction, backache and early onset of menopause. ${ }^{5-8}$ There is a further risk of developing osteoporosis and coronary artery disease, when oophorectomy is done simultaneously. ${ }^{9}$

The prevalence rate of hysterectomy in US is $26.4 \%$ and in Australia, it is between $16.9 \%$ to $22 \% .^{10-12}$ Recent studies have shown a decline in the number of hysterectomies performed in developed countries because 
of availability of less-invasive alternative treatment modalities like endometrial ablation, uterine artery embolization etc. ${ }^{13,14}$

But in developing countries, there has been a rise in the number of women undergoing hysterectomy for nononcological reasons, since most of them are of the view that uterus is dispensable after childbirth and also because they experience prompt relief from symptoms of heavy menstrual bleeding and backache as seen in fibroid and dysfunctional uterine bleeding. ${ }^{15}$ A study using data from District level household survey-4 from 21 states and union territories of India found the prevalence of hysterectomy across different states varied from 2 to $63 / 1000$ women and a higher prevalence was seen in the southern states. ${ }^{16}$

The American college of obstetricians and gynaecologists advises that proper diagnostic evaluation is done and appropriate treatments considered, before hysterectomy is recommended. ${ }^{17}$ In current study, we retrospectively analyse whether the preoperative clinical indication for hysterectomy is in tandem with the postoperative histopathology report. This helps to determine if hysterectomy was indeed essential for the patient and if any lacunae exists in preoperative evaluation so as to individualise the treatment and provide better patient care.

\section{METHODS}

This is a retrospective study conducted in the department of obstetrics and gynaecology at Indira Gandhi medical college and research institute Puducherry, over a span of one year from January 2018 to December 2018. Patients who underwent hysterectomy for non-oncological causes, by abdominal route (TAH), with or without unilateral (USO) and bilateral (BSO); and vaginal route (for both prolapse and non-descent conditions) were included in the study. Caesarean hysterectomies and hysterectomies for malignancies were excluded.

Consecutive sampling of all the eligible cases from the MRD register between January 2018 to December 2018 was done. Assuming the proportion of fibroid cases as indication for non-oncological hysterectomies as 50\%, with alpha error as $5 \%$ and absolute error of margin as $7 \%$, the calculated minimum sample size was 196, using the software OpenEpi. We took all the eligible cases and finally we had 234 cases for the study.

From the medical records department patient case records were methodically examined and data such as age of the patient, parity, preoperative diagnostic investigations done, indications for surgery and the type of hysterectomy performed was noted. The histopathology report of the resected specimen was duly noted. This was compared to the preoperative clinical diagnosis. Data was entered in MS excel and analysed using SPSS software.

\section{RESULTS}

Over the study period of one year, a total of 234 hysterectomies were performed, of which 108 (46.15\%) were by abdominal route and $126(53.84 \%)$ were by vaginal route. Of the abdominal hysterectomies, 58 $(24.7 \%)$ were TAH with BSO with mean age 49.72 years. VH with PFR $(46.5 \%)$ constituted majority of the surgeries done with mean age of 55.31 years (Table 1 ).

Table 1: Type of hysterectomy and patient's age.

\begin{tabular}{|lllll|}
$\begin{array}{l}\text { Type of } \\
\text { hysterectomy }\end{array}$ & $\begin{array}{l}\text { Age } \\
\text { (years) }\end{array}$ & $\mathbf{N}$ & $\%$ & $\begin{array}{l}\text { Mean age } \\
\text { (years) }\end{array}$ \\
\hline TAH & $38-46$ & 42 & 17.9 & 40.47 \\
\hline TAH USO & $37-42$ & 8 & 3.4 & 39.5 \\
\hline TAH BSO & $45-55$ & 58 & 24.7 & 49.72 \\
\hline VH & $43-50$ & 17 & 7.2 & 46.47 \\
\hline VH PFR & $50-65$ & 109 & 46.5 & 55.31 \\
\hline
\end{tabular}

Among the patients for whom only TAH was done, the indications were fibroid (15.3\%), DUB (1.7\%) and adenomyosis $(0.85 \%)$. Clinical diagnosis of ovarian cyst alone $(1.2 \%)$ or along with presence of fibroid $(1.2 \%)$ or adenomyosis $(0.85 \%)$ was the indication for TAH with USO. $17.9 \%$ (42) of the women, underwent TAH with BSO for fibroid. DUB (4.2\%) was the most common indication for $\mathrm{VH}$. Uterovaginal prolapse $(46.5 \%)$ was the most common gynaecological diagnosis (Table 2).

Table 2: Type of hysterectomy and clinical diagnosis $(n=234)$.

\begin{tabular}{|lll|l|}
\hline $\begin{array}{l}\text { Type of } \\
\text { hysterectomy }\end{array}$ & Clinical diagnosis & N & $\%$ \\
\hline \multirow{3}{*}{ TAH } & Fibroid & 36 & 15.3 \\
\cline { 2 - 4 } & Adenomyosis & 2 & 0.85 \\
\cline { 2 - 4 } TAH USO & DUB & 4 & 1.7 \\
\cline { 2 - 4 } & Adbroid with ovarian cyst & 3 & 1.2 \\
\hline \multirow{4}{*}{ TAH BSO } & Ovarian cyst & 2 & 0.85 \\
\cline { 2 - 4 } & Ovarian cyst & 3 & 1.2 \\
\cline { 2 - 4 } & Fibroid & 42 & 17.9 \\
\cline { 2 - 4 } & Edenomyosis & 4 & 1.7 \\
\cline { 2 - 4 } & Ondometriosis & 6 & 2.5 \\
\hline \multirow{3}{*}{ VH } & DUBian cyst & 6 & 2.5 \\
\cline { 2 - 4 } & Fibroid & 10 & 4.2 \\
\cline { 2 - 4 } & Adenomyosis & 2 & 0.85 \\
\cline { 2 - 4 } & Cervical elongation & 2 & 0.85 \\
\hline VH PFR & UVP & 109 & 46.5 \\
\hline
\end{tabular}

Out of the 80 cases $(34.18 \%)$ diagnosed clinically as fibroid, $66(28.2 \%)$ were confirmed on histopathology. Histopathological diagnosis corroborated the clinical diagnosis in patients with ovarian cyst, fibroid with ovarian cyst and DUB. Adenomyosis was validated in 7 $(2.9 \%)$ of the $9(3.8 \%)$ cases on histopathology. 
Authenticate clinical diagnosis of endometriosis of ovary was made in $4(1.7 \%)$ of the 6 cases. In patients diagnosed with pelvic organ prolapse clinically, histopathology showed atrophic changes (Table 3).

Table 3: Correlation between clinical indication and histopathology report.

\begin{tabular}{|c|c|c|c|c|c|}
\hline Clinical diagnosis $(n=234)$ & $\mathbf{N}$ & $\%$ & Histopathological diagnosis $(\mathrm{n}=\mathbf{2 3 4})$ & $\mathbf{N}$ & $\%$ \\
\hline \multirow{2}{*}{ Fibroid } & \multirow{2}{*}{80} & \multirow{2}{*}{34.18} & Leiomyoma & 66 & 28.20 \\
\hline & & & Adenomyosis & 14 & 5.98 \\
\hline \multirow{2}{*}{ Fibroid with ovarian cyst } & \multirow{2}{*}{3} & \multirow{2}{*}{1.28} & Leiomyoma with Endometriotic cyst of ovary & 2 & 0.85 \\
\hline & & & Leiomyoma with hemorrhagic cyst of ovary & 1 & 0.42 \\
\hline \multirow{2}{*}{ Adenomyosis } & \multirow{2}{*}{9} & \multirow{2}{*}{3.84} & Leiomyoma & 2 & 0.85 \\
\hline & & & Adenomyosis & 7 & 2.99 \\
\hline \multirow{2}{*}{$\begin{array}{l}\text { Adenomyosis with ovarian } \\
\text { cyst }\end{array}$} & \multirow[t]{2}{*}{2} & \multirow[t]{2}{*}{0.85} & $\begin{array}{l}\text { Proliferative endometrium, normal myometrium } \\
\text { with serous cystadenoma }\end{array}$ & 1 & 0.42 \\
\hline & & & Adenomyoma with Endometriotic cyst of ovary & 1 & 0.42 \\
\hline \multirow{3}{*}{ Endometriosis } & \multirow{3}{*}{6} & \multirow{3}{*}{2.56} & $\begin{array}{l}\text { Subserous leiomyoma with normal histology of } \\
\text { ovaries }\end{array}$ & 1 & 0.42 \\
\hline & & & Endometriotic ovarian cyst & 4 & 1.70 \\
\hline & & & TO abscess & 1 & 0.42 \\
\hline \multirow{3}{*}{ Ovarian cyst } & \multirow{3}{*}{9} & \multirow{3}{*}{3.84} & Simple serous cystadenoma & 5 & 2.13 \\
\hline & & & Mucinous cystadenoma & 3 & 1.28 \\
\hline & & & Mature cystic teratoma & 1 & 0.42 \\
\hline \multirow{5}{*}{ DUB } & \multirow{5}{*}{14} & \multirow{5}{*}{5.98} & Simple hyperplasia with atypia & 3 & 1.28 \\
\hline & & & Disordered proliferative endometrium & 5 & 2.13 \\
\hline & & & Secretory endometrium & 3 & 1.28 \\
\hline & & & Cystoglandular hyperplasia & 1 & 0.42 \\
\hline & & & Atrophic endometritis & 2 & 0.85 \\
\hline Cervical elongation & 2 & 0.85 & $\begin{array}{l}\text { Non-specific endo myometritis with atrophic } \\
\text { changes in cervix }\end{array}$ & 2 & 0.85 \\
\hline UVP & 109 & 46.58 & Atrophic changes & 109 & 46.58 \\
\hline
\end{tabular}

\section{DISCUSSION}

Hysterectomy, whatever the approach used (abdominal, vaginal, laparoscopic), remains the gold standard in the treatment of many uterine benign pathological conditions. ${ }^{18}$ According to the centres for disease control and prevention (CDC), from 2006-2010, 11.7\% of women between the ages of 40-44 years had a hysterectomy and by the age of 60 years, more than onethird of all women have had a hysterectomy. ${ }^{19}$ Although the death rate from a hysterectomy is low (less than 1\%) surgical complications are very real and can result in any of the following; infection, haemorrhage during or following surgery and/or damage to internal organs such as the urinary tract or bowel. The association between hysterectomy and early menopause has been examined in a number of studies dating back several decades. A study by Moorman et al found a nearly twofold increased risk for ovarian failure among women undergoing hysterectomy without bilateral oophorectomy as compared to women of similar age with intact uteri. ${ }^{20}$ This would lead to an increased risk of ischemic heart disease and osteoporosis. A study by Magon et al showed that hysterectomy is a surgery which has been used and misused, underused, and abused at different times in gynecology. ${ }^{21}$ A study done by Broder et al to assess the appropriateness of recommendations for hysterectomy on 497 women concluded that hysterectomy is often recommended for indications judged inappropriate. ${ }^{22} \mathrm{~A}$ study done to determine the effects of surgical menopause on sexual performance recommends that hysterectomy for benign conditions should be avoided unless there is a sound clinical indication. ${ }^{23}$ These findings suggest that hysterectomy would be unwarranted unless there is a definite indication. Moreover, the emergence of effective medical and conservative treatment for benign conditions warrants a very diligent approach in making a decision for hysterectomy. Hence this study was done in a tertiary care hospital in Puducherry to correlate the histopathological diagnosis of the postoperative specimen with the preoperative clinical diagnosis in order to determine whether the hysterectomy was justified and to obtain baseline data for formulation of future protocols.

Current study was a retrospective study done on all the cases of hysterectomy performed in the hospital over a period of one year. A total of 234 hysterectomies were performed in one year. The age of the patients ranged from 37 to 65 years with the mean age being 46.2 years. The most common procedure performed was vaginal 
hysterectomy with pelvic floor repair (46.5\%) for uterovaginal prolapse. The next most common indication for hysterectomy was found to be fibroid uterus $(34.18 \%)$.

Out of the 109 women for whom vaginal hysterectomy was performed for uterovaginal prolapse all of them were postmenopausal, above the age of 50 years. The histopathology of all the specimens showed an atrophic endometrium. There were no premalignant or malignant changes reported in the endometrium or cervix. In all these cases the histopathological findings correlated with the clinical diagnosis and the indication for surgery was justified in all these women. These findings were consistent with those of other studies, suggesting that hysterectomy is justified in elderly women with uterovaginal prolapse. ${ }^{24,25}$

The next most common indication for hysterectomy was fibroid $(34.18 \%)$. The age of the patients ranged from 37 to 55 years. All the cases except 2 were performed by the abdominal route. Out of the 80 cases of hysterectomy done for fibroid as the indication, 66 cases were confirmed to be fibroid by histopathological examination showing a correlation of $82.5 \%$. The rest $17.5 \%$ of the cases were reported to be adenomyosis. An analysis of the histopathological examination of hysterectomy done by Deepti et al showed that none of the cases of adenomyosis in their study were diagnosed preoperatively. ${ }^{25} \mathrm{~A}$ study done on the prevalence of adenomyosis in hysterectomy specimens in Pondicherry showed the prevalence to be as high as $55 \% .{ }^{26}$ These findings suggest a need for high index of suspicion and evaluation for adenomyosis in women of the younger age group and consideration of conservative measures of treatment. This could contribute to a reduction of the number of hysterectomies performed. Nevertheless, the correlation of $82.5 \%$ between the clinical and histopathological examination in our analysis shows that majority of the cases done were justified.

Dysfunctional uterine bleeding was another common indication for hysterectomy in our study. Out of the 14 cases done for DUB as the preoperative indication, 4 cases showed endometrial hyperplasia $(28.5 \%)$ of which 3 cases showed $(21.4 \%)$ atypical changes with hyperplasia. The most common histopathology of endometrium in the DUB cases was proliferative endometrium $(35.7 \%)$. The higher incidence of atypical endometrium found in this study justifies the hysterectomy done for these cases. Other studies where the percentage of hysterectomies done for DUB were greater showed a lower incidence of atypical hyperplasia. ${ }^{27}$ In our study the cases of DUB did not show any significant myometrial pathology on histopathological examination in contrast to a study done by Kaur et al which showed that a large number of cases $(78 \%)$ with a preoperative diagnosis of DUB had undetected coexistent myometrial pathology. ${ }^{28}$ This difference could be due to the routine use of transvaginal ultrasound preoperatively in all cases in our study even if an ultrasound had been performed previously during medical management of DUB. These findings suggest a definite need for endometrial biopsy in all cases of DUB and also an ultrasound examination preoperatively to rule out myometrial pathology.

Out of the 9 cases which were diagnosed as adenomyosis preoperatively, histopathological correlation was found in $77.7 \%$ of the cases. The remaining cases were reported as leiomyoma. Out of the 6 cases diagnosed clinically as endometriosis, one case showed subserous leiomyoma with normal ovaries and another case showed tuboovarian abscess. These findings suggest the need for use of preoperative diagnostic laparoscopy in cases of endometriosis before planning a definitive surgery. ${ }^{29}$

Out of the 9 cases diagnosed as ovarian cysts preoperatively, total abdominal hysterectomy with bilateral ovariotomy was done in 6 cases and total abdominal hysterectomy with unilateral ovariotomy was done in 3 cases. All the 9 cases were reported as benign ovarian cysts with no significant pathology in the uterus. These findings suggest the role of avoiding hysterectomy when unilateral ovariotomy is performed in order to preserve the function of the remaining ovary for a longer time. $^{30}$

None of the histopathological reports, except for those done for uterovaginal prolapse, showed an unremarkable pathology justifying most of the hysterectomies in our study, as indicated.

\section{Limitation}

The limitation of current study was, the histopathological diagnosis was not correlated with the clinical features. A wider future study using the clinical features, investigations and patient satisfaction following hysterectomy will give us a better understanding regarding justification of hysterectomy in benign conditions.

\section{CONCLUSION}

Careful and diligent pre-operative clinical evaluation before hysterectomy has a significant correlation with histopathological findings. Adenomyosis is the most common pathology undiagnosed preoperatively warranting a high index of suspicion and careful evaluation. Use of preoperative endometrial biopsy and transvaginal ultrasound can reduce the number of hysterectomies performed for DUB. Hysterectomy has a definitive role in the management of benign lesions of the uterus when the indication is based on sound clinical judgement.

\section{Funding: No funding sources Conflict of interest: None declared \\ Ethical approval: The study was approved by the Institutional Ethics Committee}




\section{REFERENCES}

1. Carlson KJ, Nichols DH, Schiff I. Indications for hysterectomy. N Engl J Med. 1993;328(12):856-60.

2. Carlson KJ. MD Outcomes of Hysterectomy. Clin Obstet Gynaecol. 1997;40(4):939-46.

3. Uzun R, Savaş A, Ertunç D, Tok E, Dilek S. The effect of abdominal hysterectomy performed for uterine leiomyoma on quality of life. J Gynaecol Obstet. 2009;19(1):1.

4. Kjerulff KH, Langenberg PW, Rhodes JC, Harvey LA, Guzinski GM, Stolley PD. Effectiveness of hysterectomy. Obstet Gynecol. 2000;95(3):319-26.

5. Bachmann GA. Hysterectomy, a critical review. J Reprod Med. 1990;35(9):839-62.

6. Dragisic KG, Milad MP. Sexual functioning and patient expectations of sexual functioning after hysterectomy. Am J Obstet Gynecol. 2004;190(5): 1416-8.

7. Wilmoth MC, Spinelli A. Sexual implications of gynecologic cancer treatments. J Obstet Gynecol Neonatal Nurs. 2000;29(4):413-21.

8. Farquhar CM, Sadler L, Harvey SA, Stewart AW. The association of hysterectomy and menopause: a prospective cohort study. BJOG Int $\mathrm{J}$ Obstet Gynaecol. 2005;112(7):956-62.

9. Parker WH, Broder MS, Liu Z, Shoupe D, Farquhar C, Berek JS. Ovarian conservation at the time of hysterectomy for benign disease. Obstet Gynecol. 2005;106(2):219-26.

10. Erekson EA, Weitzen S, Sung VW, Raker CA, Myers DL. Socioeconomic indicators and hysterectomy status in the United States, 2004. J Reprod Med. 2009;54(9):553-8.

11. Schofield MJ, Hennrikus DJ, Redman S, SansonFisher RW. Prevalence and characteristics of women who have had a hysterectomy in a community survey. Aust N Z J Obstet Gynaecol. 1991;31(2): 153-8.

12. Byles JE, Mishra G, Schofield M. Factors associated with hysterectomy among women in Australia. Health Place. 2000;6(4):301-8.

13. Whiteman MK, Hillis SD, Jamieson DJ, Morrow B, Podgornik MN, Brett KM, et al. Inpatient hysterectomy surveillance in the United States, 20002004. Am J Obstet Gynecol. 2008;198(1):34e1-7.

14. Stankiewicz A, Pogany L, Popadiuk C. Prevalence of self-reported hysterectomy among Canadian women, 2000/2001-2008. Chronic Dis Inj Can. 2014;34(1): 30-5.

15. Desai S, Campbell OM, Sinha T, Mahal A, Cousens S. Incidence and determinants of hysterectomy in a low-income setting in Gujarat, India. Health Policy Plan. 2017;32(1):68-78.
16. Prusty RK, Choithani C, Gupta SD. Predictors of hysterectomy among married women 15-49 years in India. ReprodHealth. 2018;15:3.

17. Van der Meij E, Emanuel MH. Hysterectomy for heavy menstrual bleeding. Womens Health. 2016;12 (1):63-9.

18. Papadopoulos MS, Tolikas AC, Miliaras DE. Hysterectomy-current methods and alternatives for benign indications. Obstet Gynecol Int. 2010;2010: 356740 .

19. Key statistics from the National survey of family growth, Atlanta, GA, Centers for disease control and prevention 2015. Available at: http://www.cdc. gov/nchs/nsfg/key_statistics/h.htm\#hysterectomy. Accessed on 20 August 2020.

20. Moorman PG, Myers ER, Schildkraut JM, Iversen ES, Wang F, Warren N. Effect of hysterectomy with ovarian preservation on ovarian function. Obstet Gynecol. 2011;118(6):1271-9.

21. Magon N, Divakar H, Kirpalni A. The use, misuse, and abuse of hysterectomy. J Mid-Life Health. 2013; 4(1): 1 .

22. Broder MS, Kanouse DE, Mittman BS, Bernstein SJ. The appropriateness of recommendations for hysterectomy. Obstet Gynecol. 2000;95(2):199-205.

23. Lonnée-Hoffmann R, Pinas I. Effects of Hysterectomy on Sexual Function. Curr Sex Health Rep. 2014;6(4):244-51.

24. Tiwana KK, Nibhoria S, Monga T, Phutela R. Histopathological Audit of 373 Nononcological Hysterectomies in a teaching hospital. Pathol Res Int.2014;2014:468715.

25. Verma D, Singh P, Kulshrestha R. Analysis of histopathological examination of the hysterectomy specimens in a north Indian teaching institute. Int $\mathbf{J}$ Res Med Sci. 2016;4(11):4753-8.

26. Koothan V, Vijay A, Maran G, Shreelakshmi L. Prevalence and burden of adenomyosis in hysterectomy specimens for benign abnormal uterine bleeding in a tertiary care institute in Pondicherry, India. Int J Reprod Contracept Obstet Gynecol. 2016;5(4):1119-23.

27. Singh P, Jaiswal VK, Garg P. Endometrial patterns in abnormal uterine bleeding. Int $\mathrm{J}$ Biomed Res. 2016;7(5):244-50.

28. Kaur S, Pandey D, Shine A. Hysterectomy for Dysfunctional Uterine Bleeding (DUB) in the era of uterine conservation. Int J Reprod Contracept Obstet Gynecol. 2015;4:1133-6.

29. Zanelotti A, Decherney AH. Surgery and Endometriosis. Clin Obstet Gynecol. 2017;60(3):477-484.

30. Khadilkar S. Does saving uterus save ovaries?. J Obstet Gynecol India. 2020;70:99-102.

Cite this article as: Kasinathan A, Nagulapally H. A retrospective study on indications and histopathological analysis of non-oncological hysterectomies in a tertiary care hospital. Int $\mathbf{J}$ Reprod Contracept Obstet Gynecol 2020;9:5050-4. 